\title{
Brachial plexopathy as a consequence of nerve root swelling after shoulder trauma in a patient following an acute seizure
}

\author{
Filip Milanovic $^{1 \oplus}$, Dusan Abramovic ${ }^{2 \oplus}$, Sinisa Ducic ${ }^{1,2 \oplus}$, Bojan Bukva ${ }^{1,2 \oplus}$, \\ Ivana Dasic ${ }^{2 \oplus}$, Tijana Radovic ${ }^{2 \oplus}$, Aline Choueiri Petermann Miskulinn ${ }^{3 \oplus}$, \\ Dejan Nikolic ${ }^{1,20}$ \\ ${ }^{1}$ Faculty of Medicine, University of Belgrade, Serbia; ${ }^{2}$ University Children's Hospital, Belgrade, Serbia; ${ }^{3}$ School of Medicine, \\ Universidade Sao Francisco, Braganca Paulista, Brasil.
}

\begin{abstract}
Background. Epileptic seizures might be associated with an increased risk of fractures, either as a result of trauma after a fall or as a result of excessive muscle contraction. In the pediatric population, excessive muscle contraction is a more significant risk factor for fractures, due to the lack of maturity in the musculoskeletal system, while antiepileptic therapy itself can lead to a reduction of bone density. Proximal humeral fractures in the pediatric population are not frequent but both proximal humeral fractures and shoulder dislocation increase the chance of brachial plexus injuries and peripheral nerve lesions.

Case. In this case report, we present a patient who suffered both avulsive greater tuberosity humeral fracture and anterior shoulder dislocation, initially diagnosed by radiography, with consequent brachial plexus injury of the left arm after an epileptic seizure followed by excessive muscle contraction. Electromyoneurography initially showed amplitudes' reduction in tested nerves along with signs of muscle denervation as well as clinical examination signs of the left arm muscular hypotrophy and hypoesthesia, especially in the left humero-scapular region. Electrotherapy and kinesitherapy as well as intramuscular dexamethasone injections administered three weeks after the injury finally improved the clinical examination findings in the patient.
\end{abstract}

Conclusion. The early detection of swelling compression, accompanied with appropriate therapy may prevent the progression of axonal damage and preserve the functional status of the affected limb.

Key words: seizure, shoulder trauma, brachial plexopathy, children.

Seizures might be associated with an increased risk of fractures, where individuals with nonepileptic seizures have a lower risk for fractures versus those with epileptic form. ${ }^{1}$ Furthermore, seizures particularly of epileptic form might cause shoulder dislocation and recurrent instability as well as arthritis. ${ }^{2-4}$ The incidence of shoulder dislocation occurring during seizures is around $0.6 \%$. A majority of these dislocations

\section{Dejan Nikolic}

denikol27@gmail.com

Received 27th March 2020, revised 29th May 2020,

2nd August 2020, 4th August 2020,

accepted 5th August 2020. are posterior but might also be anterior, although very rarely reported..$^{5-7}$ The trauma of the shoulder could be the consequence of a fall during the seizure episode, as well as the seizure itself, due to the excessive muscle contraction. ${ }^{8}$ Additionally, drug-induced reduction in bone mineral density could increase the risk for fractures in these patients. ${ }^{9}$

Fractures and dislocations in the shoulder region could cause lesions of the brachial plexus to a various degree. ${ }^{7}$ Fernandez-Torre et al. ${ }^{10}$ reported a rare brachial plexopathy in an adult patient as a consequence of a generalized tonic-clonic seizure. Early recognition of brachial plexus lesions is important for the 
on-time inclusion of the proper treatment and rehabilitation. These plexopathies if not recognized and treated timely, might lead to a chronic disability with additional complications ${ }^{11}$, affecting the patients' quality of life.

In this case report, we present a patient who developed shoulder trauma with both anterior shoulder dislocation, proximal humeral fracture and injury of the brachial plexus of the left arm during the acute episode of a seizure.

\section{Case Report}

A sixteen-year old adolescent was admitted to the University Children's Hospital. He was conscious with pain, paresthesia and muscle weakness in the upper left limb, had a tongue wound and had an antalgic body position. The symptoms such as disorientation and generalized seizure in a supine position on the left flank began on the day of admission. The seizure which was not followed by involuntary urination and defecation but with hypersalivation lasted around ninety seconds and ceased after oral midazolam administration. Cefixime antibiotic therapy was initiated five days before the seizure due to a diagnosed sinusitis, all the time without fever. Clinical and diagnostic monitoring of the patient had started four years before the seizure, after having the first of his four afebrile crises of consciousness, when oral clobazam and benzodiazepine therapy was initiated despite the fact that all computed tomography and electroencephalography results were within the reference range. On the admission day, the patient took zinc instead of clobazam by mistake. Heteroanamnestic data revealed no evidence of allergies to any food or medicine. The patient was in the normal state of consciousness, properly responsive, afebrile, eupneic, acyanotic and anicteric. Neurological findings included an antalgic position of both body and left arm, where weakness of the muscle, pain and paresthesia were present. Only a minimal ability to move his fingers was present, while muscle strength, tone, mobility and sensibility were all significantly impaired compared to the right arm. Neurological exam including cranial nerves was normal and there were no meningeal irritation signs. There were no signs of neurovascular compromise of the left arm: distal pulses were palpable and there was neither swelling nor skin discoloration.

Family history anamnesis revealed no specific information. Neurological development of the patient was compatible with his age and gender, excluding above mentioned afebrile crises of consciousness. All of his immunizations were on schedule with no recent immunization.

All laboratory blood tests showed no significant deviance, as well as biochemical tests, excluding minimally increased levels of glucose -8.6 $\mathrm{mmol} / \mathrm{l}$ and C-reactive protein $-5.9 \mathrm{mg} / \mathrm{l}$. Initial radiography demonstrated the presence of the left shoulder dislocation.

On admission to the hospital, initial radiography imaging was performed (Fig. 1). The proximal humerus was in an internal rotation position. The fractured fragment of the proximal humerus included greater tuberosity and was dislocated anteriorly and caudally around five millimeters. Orthopedic

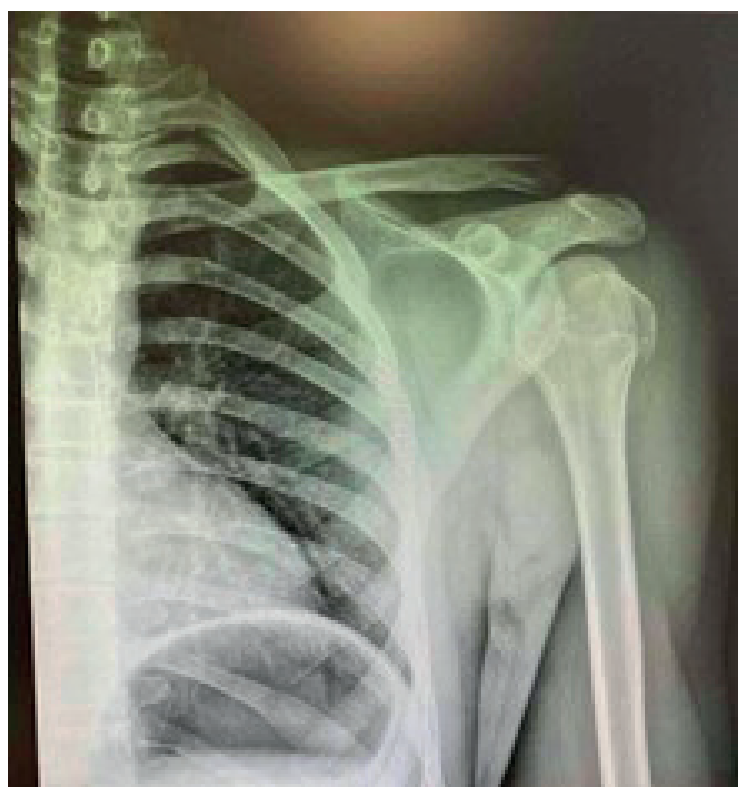

Fig. 1. Plain radiography of the left shoulder.

The Turkish Journal of Pediatrics • January-February 2021 
reposition was performed and the patient's left arm was immobilized with a plaster splint in the position of elbow semiflexion as well as internally rotated in the shoulder. The patient was referred for further physical therapy and rehabilitation treatment.

Electroneurographydiagnosticswereperformed on the left upper limb both 2 weeks and 1 month after the trauma. On the first exam, the axillar nerve of the left arm was unresponsive to supramaximal stimuli, while motor amplitudes for ulnar, median and radial nerve on the left side were reduced, with the radial nerve being most severely affected (Table I). Sensory nerves (median, ulnar and radial) were affected as well, with reduced sensory amplitude and slightly reduced sensory conduction velocities (SCV) for median nerve and border SCV for ulnar and radial nerve (Table I). In all tested muscles of the left upper limb on the first exam, pathological spontaneous activity was detected, with no activity for voluntary muscle contraction of the deltoid muscle, and severely reduced trace for all other tested muscles (Table II). Manual Muscular Test (MMT) on the left hand showed the presence of reduced strength two weeks after trauma. For fingers and hand extensors the grade was 0 out of 5 (the patient could neither extend left hand nor fingers); for fingers abductors the grade was $1 / 2$ out of 5 (there was slight abduction of fingers on the left arm with low amplitude in active motion range), while for fingers flexors the grade was 3 out of 5 (the flexion of left hand in the wrist was possible, but the patient could not hold the subjects). Sensory disturbances were present as well in the areas of tested nerves innervation of left hand and fingers.

On the second exam, for motor nerves, there was an improvement noticed in amplitudes and motor conduction velocities for the median nerve (Table I). For sensory nerves, improvements in amplitudes were noticed for ulnar and radial nerve and sensory conduction velocities for all tested sensory branches (Table I). Despite the present of spontaneous

Table I. Nerve conduction studies values.

\begin{tabular}{|c|c|c|c|c|c|c|c|}
\hline \multicolumn{2}{|c|}{ Nerves } & \multicolumn{3}{|c|}{ Left arm } & \multicolumn{3}{|c|}{ Right arm } \\
\hline \multicolumn{8}{|c|}{ Motor nerves } \\
\hline Nerve & Exam & $\begin{array}{c}\text { Distal latency } \\
(\mathrm{ms})\end{array}$ & $\begin{array}{l}\text { Amplitude } \\
(\mathrm{mV})\end{array}$ & $\begin{array}{l}\mathrm{MCV} \\
(\mathrm{m} / \mathrm{s})\end{array}$ & $\begin{array}{l}\text { Distal latency } \\
\text { (ms) }\end{array}$ & $\begin{array}{l}\text { Amplitude } \\
(\mathrm{mV})\end{array}$ & $\begin{array}{l}\mathrm{MCV} \\
(\mathrm{m} / \mathrm{s})\end{array}$ \\
\hline \multirow{2}{*}{$\begin{array}{l}\text { Median } \\
(\mathrm{APB})\end{array}$} & First & 3.7 & 3.7 & 47.5 & 4.0 & 10.0 & 55.1 \\
\hline & Second & 3.7 & 6.6 & 54.2 & - & - & - \\
\hline \multirow{2}{*}{$\begin{array}{c}\text { Ulnar } \\
(\mathrm{ADM})\end{array}$} & First & 2.9 & 2.9 & 60.5 & 3.2 & 10.0 & 64.7 \\
\hline & Second & 2.5 & 5.0 & 51.3 & - & - & - \\
\hline \multirow{2}{*}{$\begin{array}{c}\text { Radial } \\
(\text { EIP) }\end{array}$} & First & 5.8 & 0.3 & - & 2.7 & 2.5 & - \\
\hline & Second & 2.6 & 2.0 & & - & - & - \\
\hline \multicolumn{8}{|c|}{ Sensory nerves } \\
\hline Nerve & Exam & $\begin{array}{l}\text { Latency } \\
\text { (ms) }\end{array}$ & $\begin{array}{l}\text { Amplitude } \\
(\mu \mathrm{V})\end{array}$ & $\begin{array}{l}\mathrm{SCV} \\
(\mathrm{m} / \mathrm{s})\end{array}$ & $\begin{array}{l}\text { Latency } \\
\text { (ms) }\end{array}$ & $\begin{array}{l}\text { Amplitude } \\
(\mu \mathrm{V})\end{array}$ & $\begin{array}{l}\text { SCV } \\
(\mathrm{m} / \mathrm{s})\end{array}$ \\
\hline \multirow{2}{*}{$\begin{array}{l}\text { Median } \\
\text { (Ring) }\end{array}$} & First & 3.0 & 4.6 & 47.5 & - & - & - \\
\hline & Second & 2.8 & 4.1 & 50.0 & - & - & - \\
\hline \multirow{2}{*}{$\begin{array}{l}\text { Ulnar } \\
\text { (Ring) }\end{array}$} & First & 2.8 & 2.9 & 50.0 & - & - & - \\
\hline & Second & 2.3 & 6.3 & 60.9 & - & - & - \\
\hline \multirow{2}{*}{$\begin{array}{l}\text { Radial } \\
\text { (Thumb) }\end{array}$} & First & 2.9 & 4.2 & 49.1 & - & - & - \\
\hline & Second & 2.2 & 5.2 & 54.5 & - & - & - \\
\hline
\end{tabular}

APB: adductor pollicis brevis muscle, ADM: abductor digiti minimi muscle, EIP: extensor indicis proprius muscle, Ring: ring finger, Thumb: thumb finger. 
Table II. Electromyographic findings.

\begin{tabular}{|c|c|c|c|c|c|c|}
\hline \multirow{3}{*}{$\begin{array}{l}\text { Muscles } \\
\text { Left arm }\end{array}$} & \multicolumn{3}{|c|}{ First exam } & \multicolumn{3}{|c|}{ Second exam } \\
\hline & \multicolumn{2}{|c|}{ Spontaneous activity } & \multirow{2}{*}{$\begin{array}{c}\text { Recruitment } \\
\text { pattern }\end{array}$} & \multicolumn{2}{|c|}{ Spontaneous activity } & \multirow{2}{*}{$\begin{array}{c}\text { Recruitment } \\
\text { pattern }\end{array}$} \\
\hline & FP & PSW & & $\mathrm{FP}$ & PSW & \\
\hline Biceps & + & + & 1-2 MU & $+/++$ & + & --/--- \\
\hline Deltoid & + & + & No activity & $+/++$ & + & $2 \mathrm{MU}$ \\
\hline Triceps & + & / & 1-2 MU & ++ & / & $2 \mathrm{MU}$ \\
\hline EDC & + & + & 1-2 MU & $+/++$ & $+/++$ & --- \\
\hline FDI & + & + & $2 \mathrm{MU}$ & $+/++$ & / & --- \\
\hline $\mathrm{APB}$ & + & + & --/--- & NP & NP & NP \\
\hline
\end{tabular}

FP: fibrillation potentials, PSW: positive sharp waves, AMP: amplitude, DUR: duration, PPP: polyphasic, EDC: extensor digitorum communis muscle, FDI: first dorsal interosseus muscle, APB: adductor pollicis brevis muscle, MU: motor units, NP: not performed.

activity in all tested muscles, signs of voluntary muscle action were improved on the second examination (Table II). Further, MMT grade for fingers extensors was 1 out of 5 and for hand extensors was $1 / 2$ out of 5 (there was an initial active extension of the left hand and extension of fingers); for fingers abductors the grade was 2 out of 5 (increase in amplitudes of active fingers abduction of the left hand was observed), while for fingers flexors the grade was $3 / 4$ out of 5 (the patient could form the wrist on left hand and hold the subjects in). Improvements of sensory disturbances was noticed particularly for the median nerve.
The overall electroneurographic findings pointed to the presence of severe, predominantly axonal lesion of motor branches of the radial and axillar nerve and moderate to moderately severe degree of a predominantly axonal lesion for motor branches of the median and ulnar nerve of the left hand. Furthermore, findings pointed out the presence of sensory neuropathy for tested nerves of the left hand.

Magnetic resonance imaging revealed the presence of posttraumatic signs of the plexus traction, in the form of edema of the lower and middle trunk and posterior cord as well as in radial and ulnar nerve (Fig. $2-$ a, b, c).

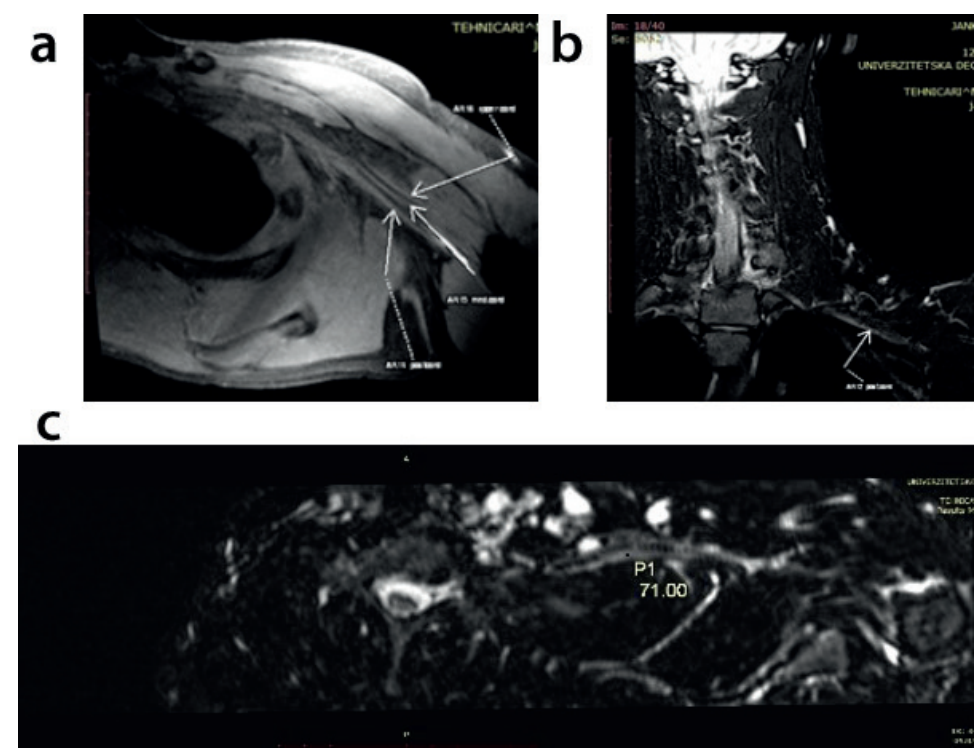

Fig. 2. a) MRI projection of three brachial plexus cords; b) MRI projection of brachial plexus posterior cord and c) MRI projection of brachial plexus posterior cord volume. 
Physical therapy was administered two weeks after the injury, five days a week, including electrotherapy (electrostimulation for fingers abductors and extensors and hand extensors), as well as kinesitherapy (passive range of motion of affected distal parts of hand and fingers, particularly extension, and active flexion of fingers) during three weeks. Clinical examination revealed muscular hypotrophy in the left humero-scapular region (Fig. 3).

Three weeks after the injury and followed by MRI findings, dexamethasone intramuscular therapy was administered in the dosage of four milligrams for three days.

The parents and patient were informed about the purpose of the case report presentation and informed consent was obtained.

\section{Discussion}

Proximal humeral fractures in the pediatric population are not frequent, comprising around $2 \%$ of all fracture subtypes in children. ${ }^{12}$ Shoulder dislocation as well as proximal humeral fractures increase the chance of brachial plexus injury as well as isolated peripheral nerve lesions. However, traumatic brachial plexus injuries are rare in children, and their prevalence is reported to be ten times

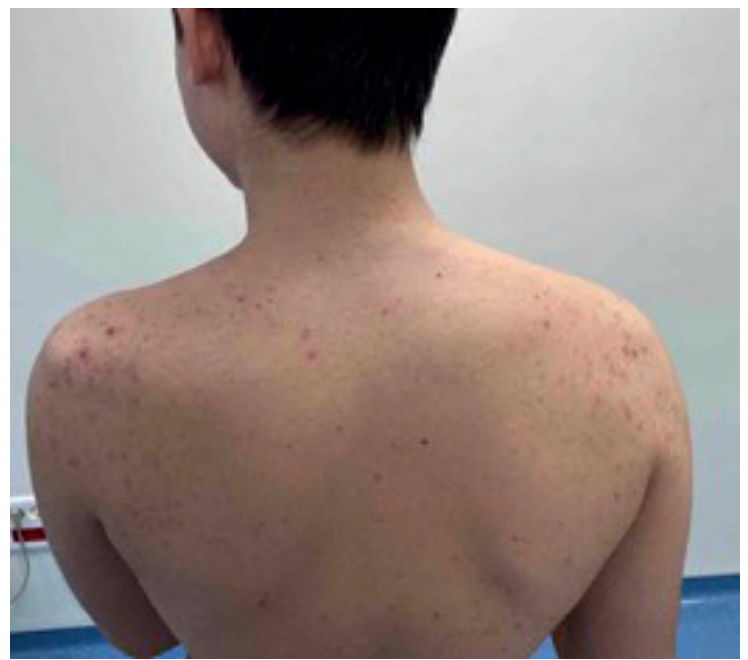

Fig. 3. Muscular hypotrophy of the left humeroscapular region. lower than in adults with multitrauma. ${ }^{13}$ Aside orthopedic trauma, vascular events could be additional factors that influence not only the onset of brachial plexus injury but its severity degree. Furthermore, for patients with seizures, excessive muscle contractions may contribute to a certain degree of brachial plexus or various isolated peripheral nerve damage as well. Since there was no data of trauma or fall, the possible explanation for the mechanism of proximal humeral fracture in this patient was thought to be excessive muscle contractions in this area during the seizure event.

Brachial plexus injuries can be divided according to the level of injury as supraclavicular and infraclavicular injuries. ${ }^{14}$ Hems and Mahmood stated in their study that for patients with a shoulder dislocation and infraclavicular type of brachial plexus injury most cases do not require surgical intervention, but it should be noticed that the need for surgical intervention might be predicted by the pattern of nerve and skeletal injury..$^{14}$ However, functional reduction of the affected upper limb should be assessed and these patients should be included in physical therapy and rehabilitation program. The administration of dexamethasone along with physical therapy of the affected upper limb in our patient accelerated functional status improvement, possibly by the mechanism of nerves swelling reduction, consequently reducing mechanical pressure on axons and by implementing electrotherapy for muscle activity and vascular circulation improvement.

Early detection of nerve lesions presence in pediatric patients is the major cornerstone for proper treatment planning and optimal functional recovery. Aside from displaced fragments, the pain in the acute phase might be one of the limiting factors that influence the motoric assessment of affected upper extremity movements in affected joints. Therefore, neurophysiological evaluations (electromyoneurography - EMNG) are vital in the process of detection of peripheral nerve damage and its severity degree, with an optimal time of performance between 2-3 weeks for 
assessment of axonal lesions. ${ }^{15}$ If there is axonal damage, 10-21 days after the injury, the spontaneous pathological activity (fibrillation potentials and positive sharp waves) will appear during the muscle evaluation at rest by needle electrode. ${ }^{15}$ Electromyoneurography is also an important diagnostic tool in the follow-up of these patients, where signs of reinnervation particularly in severe cases can be detected prior to the clinical signs of improvement.

Clinical symptoms of brachial plexus lesions are not just a consequence of the direct trauma but may be a consequence of the swelling compression of nerves. Having this in mind, swelling might be a potential cause of the functional deterioration in the pediatric population with seizure events. Additionally, a significant risk factor in the pediatric population is musculoskeletal immaturity, thus insufficient biomechanical joint stability that could be infringed by an acute seizure episodes. Therefore, early detection of the swelling compression, accompanied with proper therapy may prevent the progression of axonal damage and preserve the functional status of the affected upper limb.

\section{REFERENCES}

1. Ach K, Slim I, Ajmi ST, Chaieb MC, Beizig AM, Chaieb L. Non-traumatic fractures following seizures: two case reports. Cases J 2010; 3: 30.

2. Bühler M, Gerber C. Shoulder instability related to epileptic seizures. J Shoulder Elbow Surg 2002; 11: 339-344.

3. Thangarajah T, Lambert SM. Management of recurrent shoulder instability in patients with epilepsy. J Shoulder Elbow Surg 2016; 25: 1376-1384.

4. Thangarajah $\mathrm{T}$, Falworth $\mathrm{M}$, Lambert SM. Anatomical shoulder arthroplasty in epileptic patients with instability arthropathy and persistent seizures. J Orthop Surg (Hong Kong) 2017; 25: 2309499017717198.
5. Goudie EB, Murray IR, Robinson CM. Instability of the shoulder following seizures. J Bone Joint Surg Br 2012; 94: 721-728.

6. Suryavanshi A, Mittal A, Dongre S, Kashyap N. Bilateral anterior shoulder dislocation with symmetrical greater tuberosity fracture following seizure. J Orthop Case Rep 2012; 2: 28-31.

7. Ahmad K, Ayaz SB, Khalil HB, Matee S. Bilateral spontaneous anterior shoulder dislocation: a missed orthopedic injury mistaken as proximal neuropathy. Chin J Traumatol 2017; 20: 370-372.

8. Camfield C, Camfield P. Injuries from seizures are a serious, persistent problem in childhood onset epilepsy: a population-based study. Seizure 2015; 27: 80-83.

9. Wirrell EC. Epilepsy-related injuries. Epilepsia 2006; 47 (Suppl 1): 79-86.

10. Fernández-Torre JL, Vázquez JL, Leno C. Brachial plexopathy following a generalized tonic-clonic seizure. Eur J Neurol 2007; 14: e14.

11. Singer AD, Meals C, Kesner V, et al. The multidisciplinary approach to the diagnosis and management of nonobstetric traumatic brachial plexus injuries. AJR Am J Roentgenol 2018; 211: 1319-1331.

12. Jovanovich EN, Howard JF Jr. Brachial plexus injury in a 6 -year-old boy with $100 \%$ displaced proximal humeral metaphyseal fracture: a case presentation. PM R 2017; 9: 1294-1298.

13. Dorsi MJ, Hsu W, Belzberg AJ. Epidemiology of brachial plexus injury in the pediatric multitrauma population in the United States. J Neurosurg Pediatr 2010; 5: 573-577.

14. Hems TE, Mahmood F. Injuries of the terminal branches of the infraclavicular brachial plexus: patterns of injury, management and outcome. J Bone Joint Surg Br 2012; 94: 799-804.

15. Gagliardo A, Toia F, Maggi F, Mariolo AV, Cillino M, Moschella F. Clinical neurophysiology and imaging of nerve injuries: preoperative diagnostic work-up and postoperative monitoring. Plast Aesthet Res 2015; 2: 149-155. 